\title{
Lateral Growth of Uniformly Thin Gold Nanosheets Facilitated by Two-dimensional Precursor Supply
}

Koki Sasaki, Tsuyoshi Okue, Takuto Nakai, Yoshiaki Uchida,* and Norikazu Nishiyama

Graduate School of Engineering Science, Osaka University, 1-3 Machikaneyama-cho, Toyonaka, Osaka 560-8531, Japan

\section{Supporting Information}

Table of Contents

\section{Characterization methods}

Figure S1. The spectrum of the light source used for the reaction.

Figure S2. Photographs of hyperswollen lyotropic lamellar phases of the reaction mixtures.

Figure S3. Characterization of Au fine particles.

Figure S4. TEM photograph and electron diffraction pattern of AuNSs.

Table S1. XRD peak positions and integration widths for AuNSs and Au fine particles.

Figure S5. Williamson-Hall plot of AuNSs and Au fine particles.

Figure S6. SEM-EDX spectra of AuNSs.

Figure S7. Photographs of the suspensions of AuNSs with various solvents.

Figure S8. Size distributions of AuNSs in the suspensions.

Figure S9. AFM photographs and cross-sections of AuNSs collected from the suspensions.

Figure S10. Dependence of width and thickness of AuNSs on $t_{\mathrm{r}}$ and $L$.

Table S2. Synthetic conditions for AuNSs in a decane solution of SOBS

Figure S11. Size distributions of AuNSs in the suspensions.

Figure S12. Dependence of width and thickness of AuNSs on $I$.

Figure S13. Dependence of volume of AuNSs on $c$.

Figure S14. Dependence of width and thickness of AuNSs on $c$.

Table S3. Dependence of Reynolds numbers on the length of the agitator.

Figure S15. Photographs of hyperswollen lyotropic lamellar phases of the reaction mixtures.

Figure S16. Polarized photographs of hyperswollen lyotropic lamellar phases.

Table S4. Synthetic conditions for AuNSs in a decane solution of Brij L4.

Figure S17. Size distributions of AuNSs in the suspensions.

Figure S18. Dependence of width and thickness of AuNSs on $t_{\mathrm{r}}$ and $L$.

Figure S19. Photographs of hyperswollen lyotropic lamellar phases of the reaction mixtures.

Figure S20. Polarized photographs of hyperswollen lyotropic lamellar phases.

Figure S20. TEM photograph and electron diffraction pattern of AgNSs. 


\section{Characterization methods}

X-ray Diffraction (XRD) Measurements

The crystal structures were estimated from XRD patterns collected using a PANalytical X'Pert PRO diffractometer with $\mathrm{Cu} \mathrm{K} \alpha$ radiation, operated at $45 \mathrm{kV}$ and $40 \mathrm{~mA}$. The scan range was from $30^{\circ}$ to $90^{\circ}$ ( 2 theta) at $0.10^{\circ} / \mathrm{s}$. The full width at half maximum was calculated using X'Pert Data Viewer.

\section{Dynamic Light Scattering (DLS)}

The distributions of AuNSs were measured by DLS using ELSZ-2000 (Otsuka Electronics Co., Ltd.) at $25^{\circ} \mathrm{C}$.

\section{Atomic Force Microscopy (AFM)}

AFM images were obtained using a Veeco Instruments MMAFM-2. The samples were deposited on freshly exfoliated mica sheets as substrates. We measure 30 samples and calculated the average and standard deviation of the size and thickness, respectively.

Scanning Electron Microscope and Energy Dispersive X-ray (SEM-EDX) spectroscopy SEM-EDX spectra were obtained using a JEOL JCM-7000 microscope at $15 \mathrm{kV}$.

\section{Transmission Electron Microscopy (TEM)}

TEM images were obtained using a Hitachi H-800 at $200 \mathrm{kV}$. 


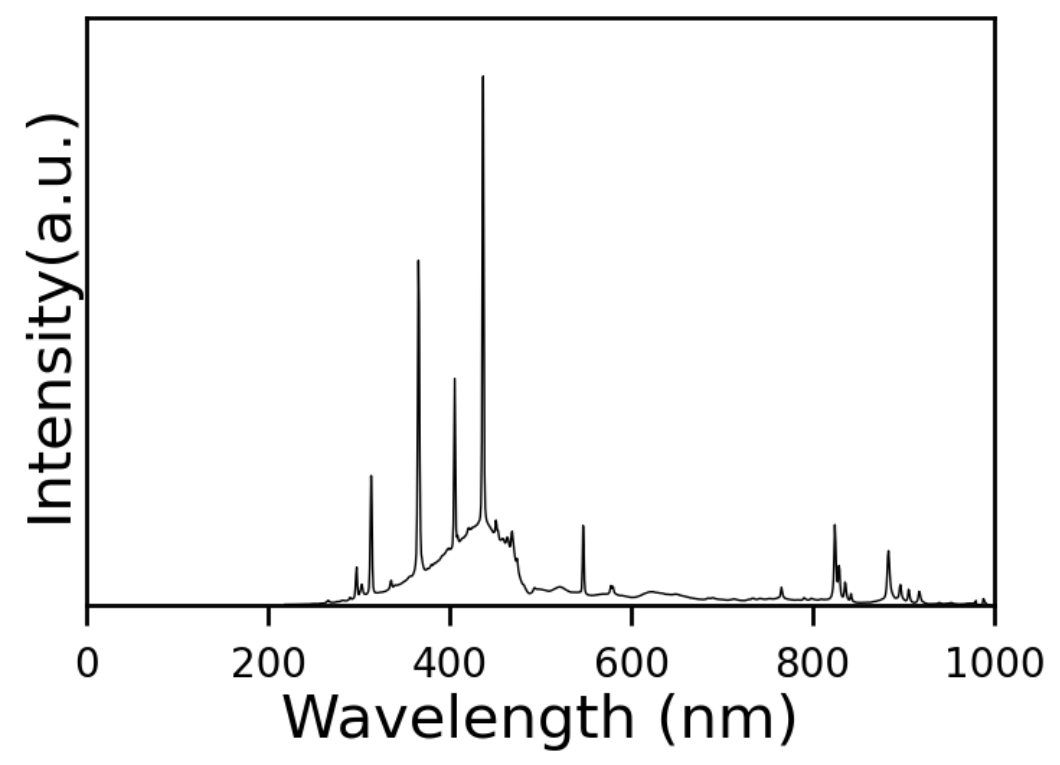

Figure S1. The spectrum of the light source used for the reaction.
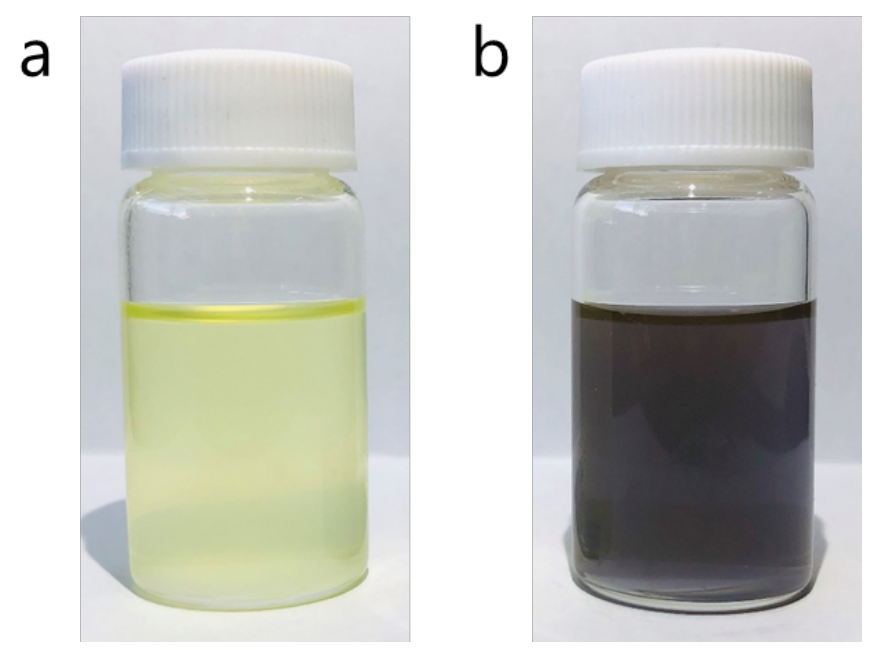

Figure S2. Photographs of hyperswollen lyotropic lamellar phases of the reaction mixtures. These are decane solutions of SOBS (0.95 wt\%), 1-pentanol (8.4 wt\%), water $(1.1 \mathrm{wt} \%)$, and $\mathrm{HAuCl}_{4}\left(5.0 \times 10^{-2} \mathrm{wt} \%\right)$. The photographs were taken (a) before the reaction and (b) after the reaction. 


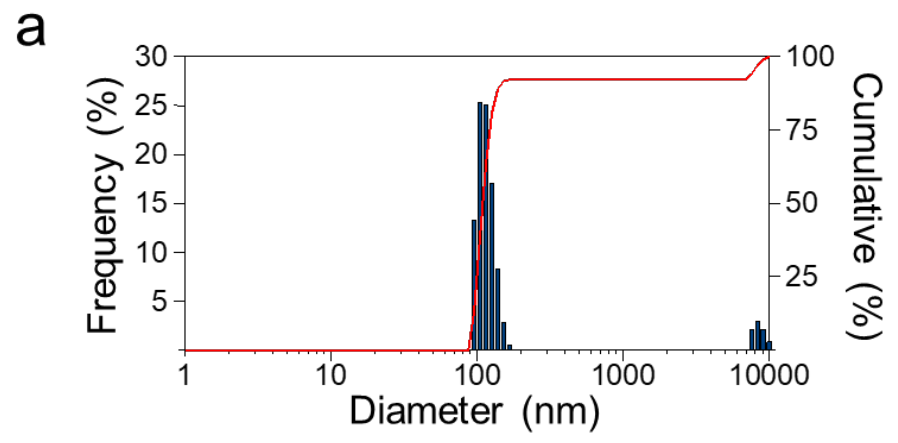

b
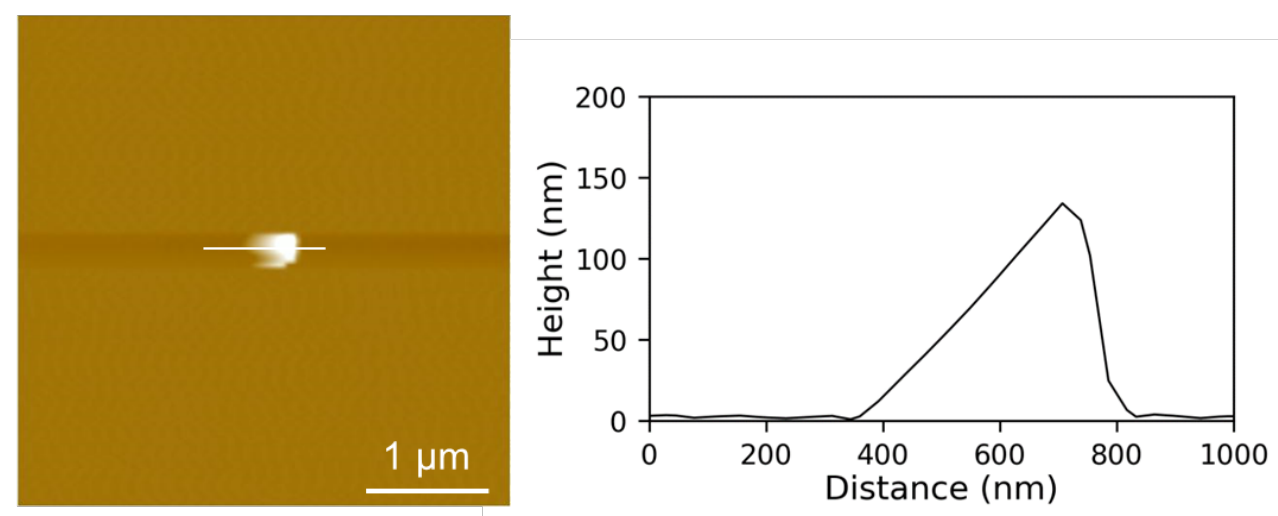

Figure S3. Characterization of Au fine particles. (a) Size distributions of $\mathrm{Au}$ fine particles in a suspension. (b) AFM photograph and cross-section of one of the synthesized Au fine particles. 

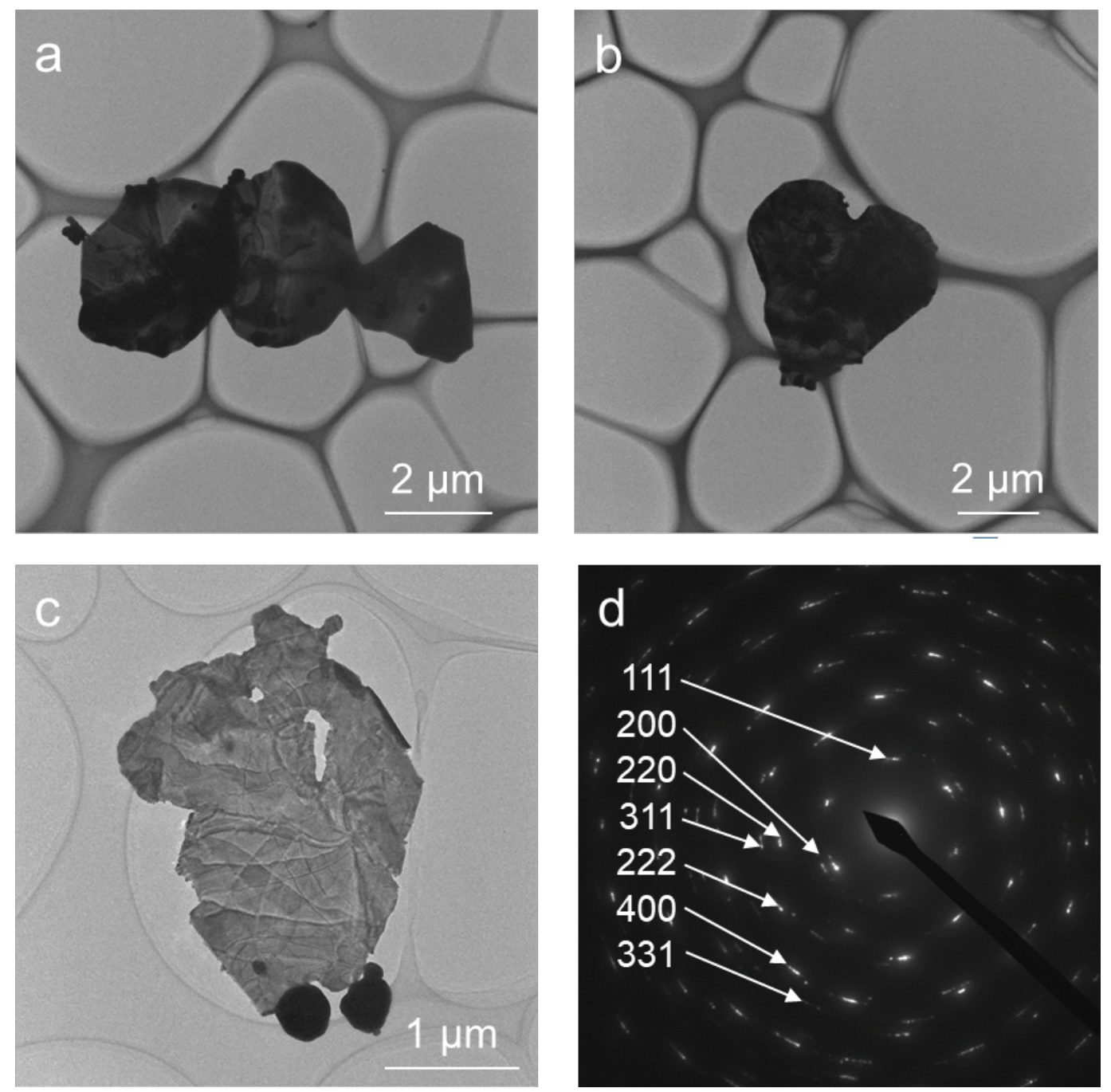

Figure S4. (a)-(c) TEM photographs and (d) selected area electron diffraction pattern of AuNSs.

Table S1. XRD peak positions and integration widths for AuNSs and Au fine particles.

\begin{tabular}{ccc} 
& \multicolumn{2}{c}{ Full width at half maximum $\left({ }^{\circ}\right)$} \\
\cline { 2 - 3 } 38.2 & AuNSs & Fine particles \\
44.4 & 0.286 & 0.253 \\
64.6 & 0.420 & 0.370 \\
77.6 & 0.487 & 0.458 \\
81.8 & 0.635 & 0.544 \\
& 0.543 & 0.517
\end{tabular}




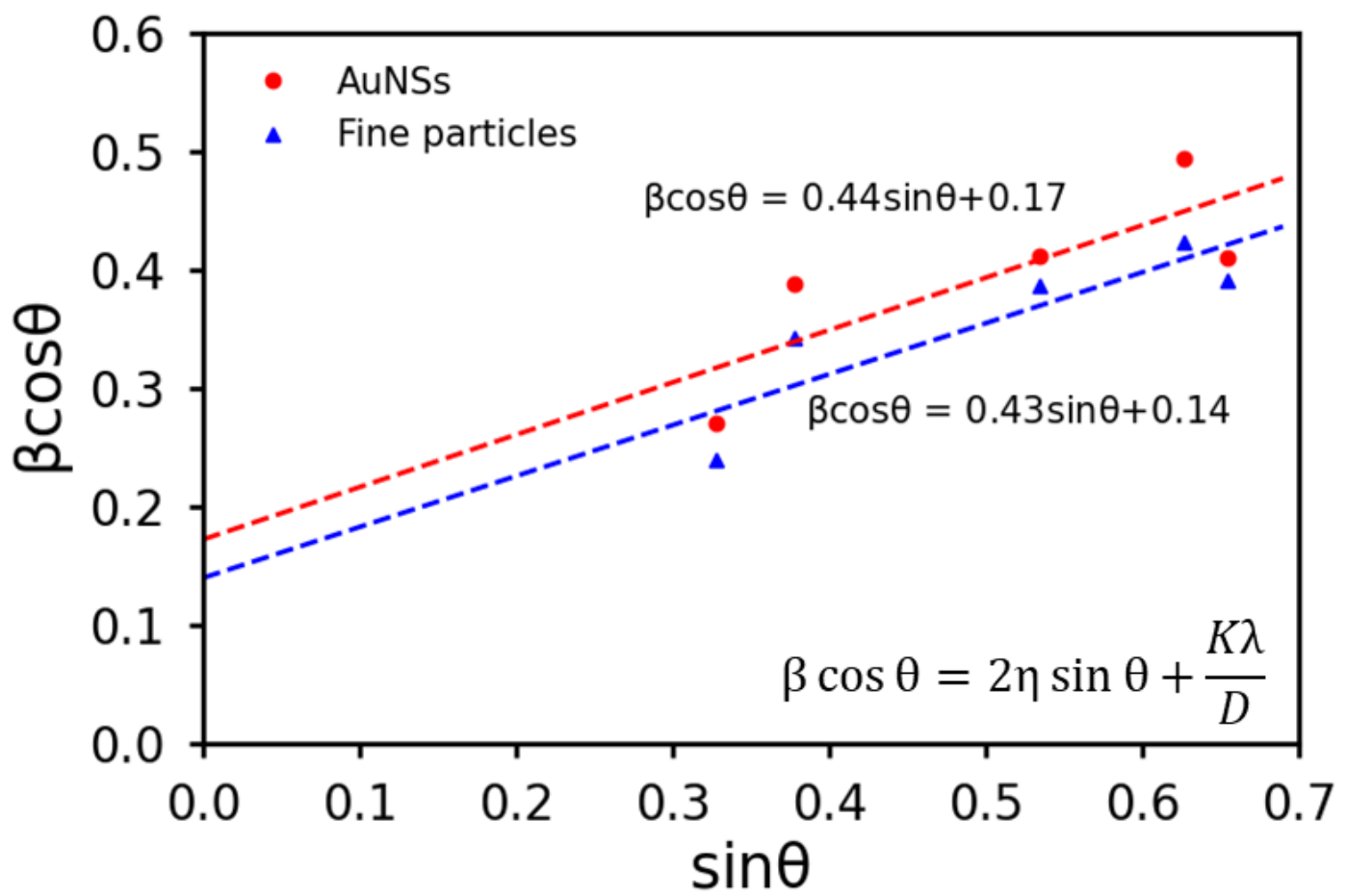

Figure S5. Williamson-Hall plots of AuNSs and Au fine particles. ${ }^{\mathrm{S} 1}$ In the equations, $\beta$ is integration width, $\eta$ is internal strain, $K$ is Scherrer constant, $\lambda$ is the $X$-ray wavelength, and $D$ is crystallite size. The Scherrer constant used was 0.94 for cubic symmetry. The estimated $D$ for AuNSs and Au fine particles are $0.84 \mathrm{~nm}$ and $1.04 \mathrm{~nm}$, respectively. 


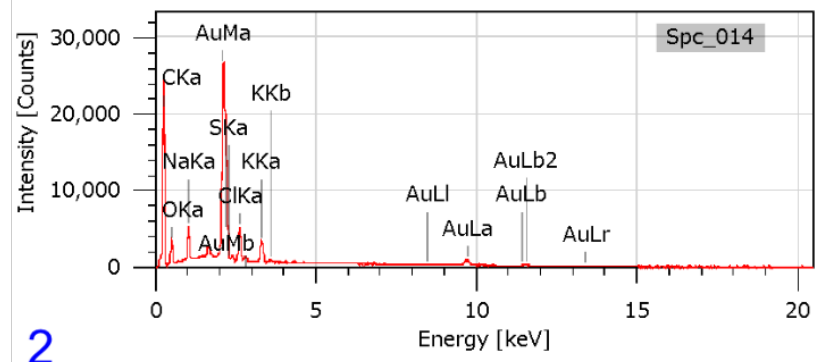

$\begin{array}{ccc}\text { Element } & \text { Mass\% } & \text { Atom\% } \\ \mathrm{C} & 41.1 & 77.8 \\ \mathrm{O} & 7.9 & 11.3 \\ \mathrm{Na} & 2.4 & 2.4 \\ \mathrm{~S} & \mathrm{Nd} & \mathrm{Nd} \\ \mathrm{Cl} & 3.3 & 2.1 \\ \mathrm{~K} & 2.7 & 1.5 \\ \mathrm{Au} & 42.6 & 4.9\end{array}$

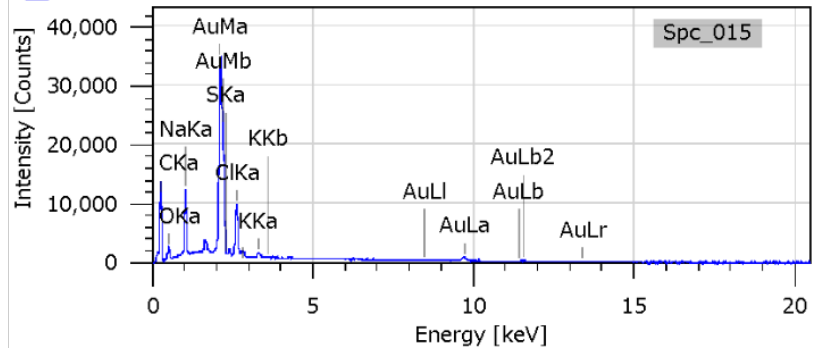

$\begin{array}{ccc}\text { Element } & \text { Mass\% } & \text { Atom\% } \\ \mathrm{C} & 28.1 & 69.7 \\ \mathrm{O} & 4.5 & 8.3 \\ \mathrm{Na} & 5.8 & 7.5 \\ \mathrm{~S} & \mathrm{Nd} & \mathrm{Nd} \\ \mathrm{Cl} & 6.8 & 5.7 \\ \mathrm{~K} & 0.8 & 0.6 \\ \mathrm{Au} & 54.0 & 8.2\end{array}$

Figure S6. SEM-EDX spectra of AuNSs.

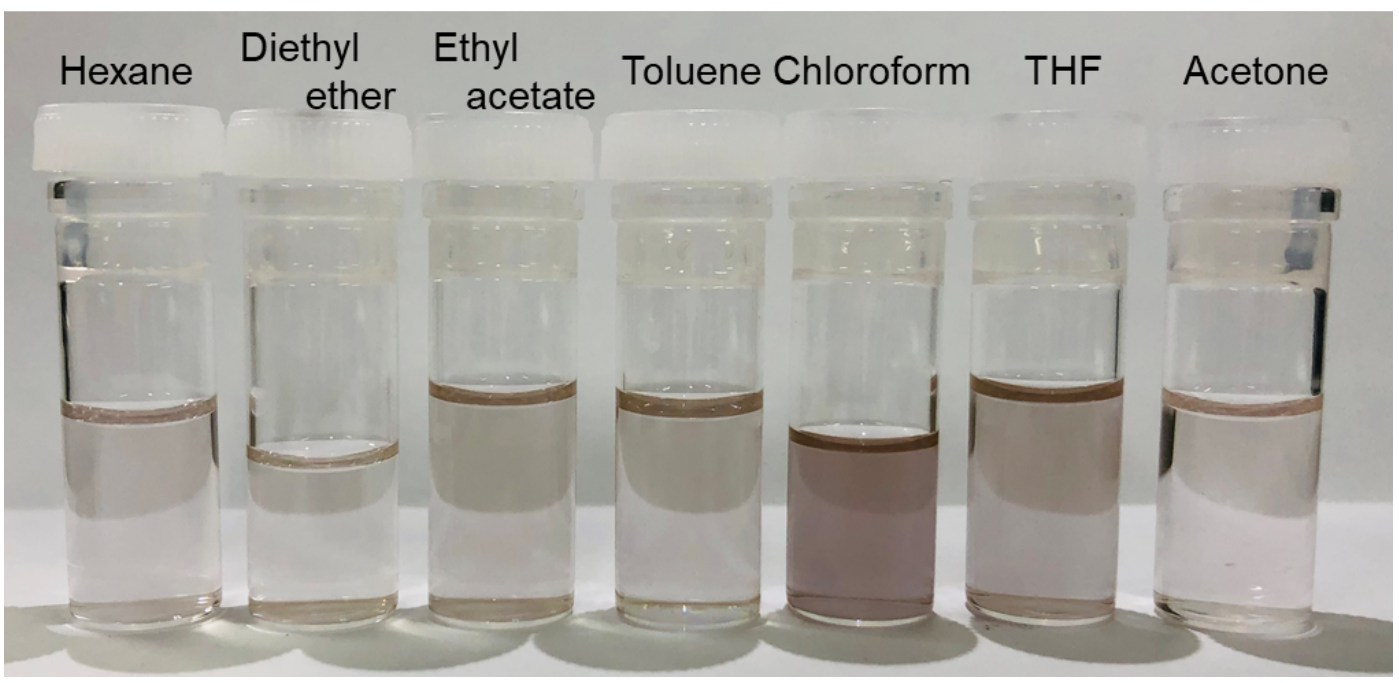

Figure S7. Photographs of the saturated suspensions of AuNSs with various solvents. 
a

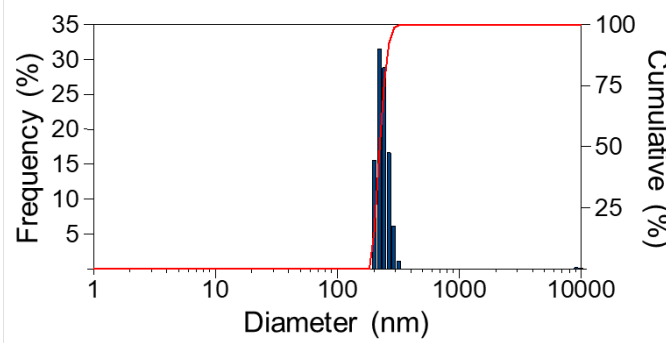

C
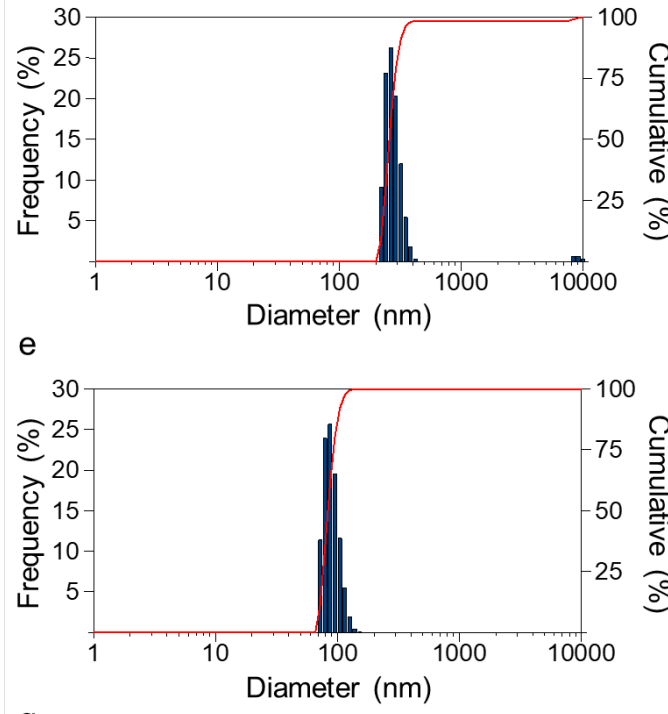

g

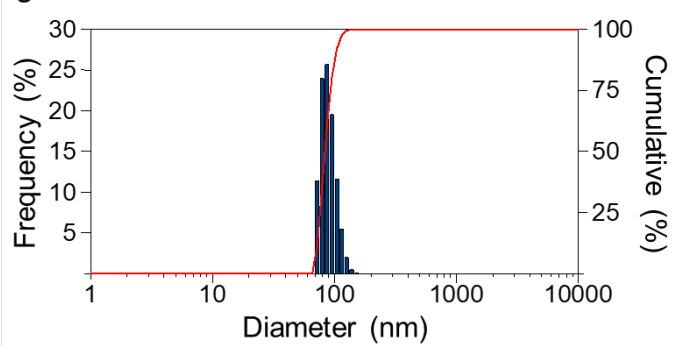

b

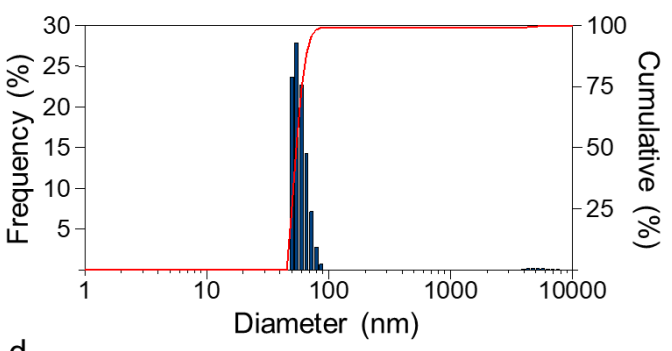

d

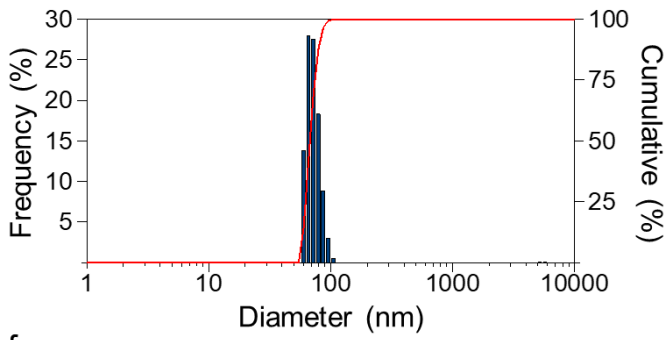

f

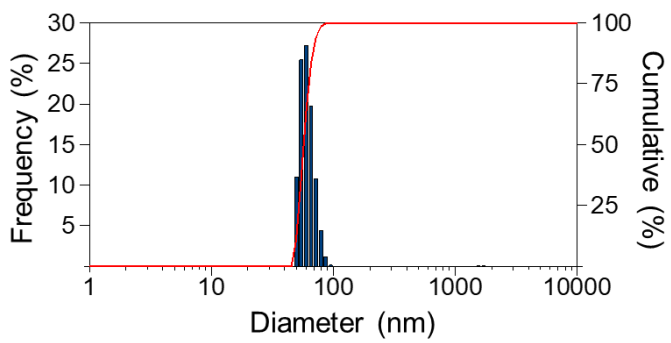

Figure S8. Size distributions of AuNSs in the suspensions. The solvents are (a) hexane, (b) diethyl acetate, (c) ethyl acetate, (d) toluene, (e) chloroform, (f) THF, and (g) acetone. 

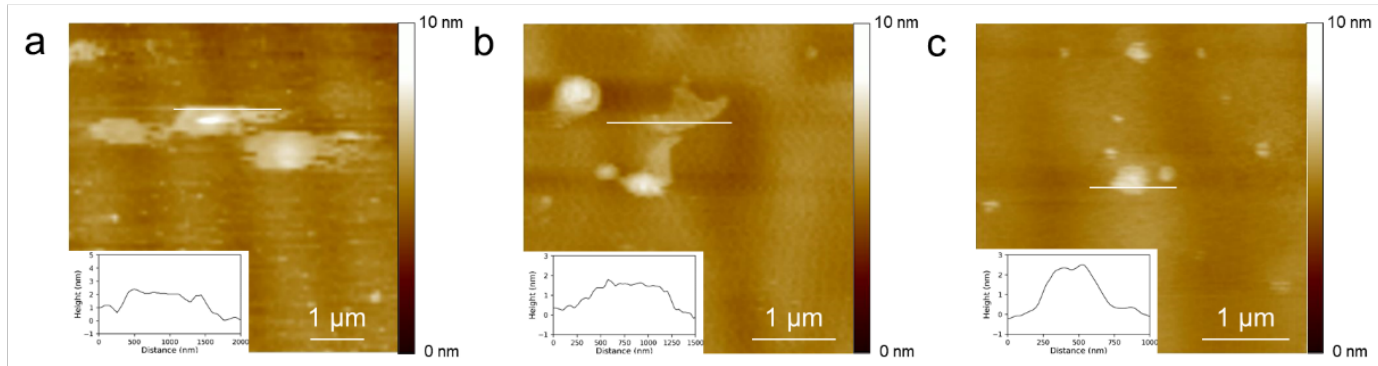

d
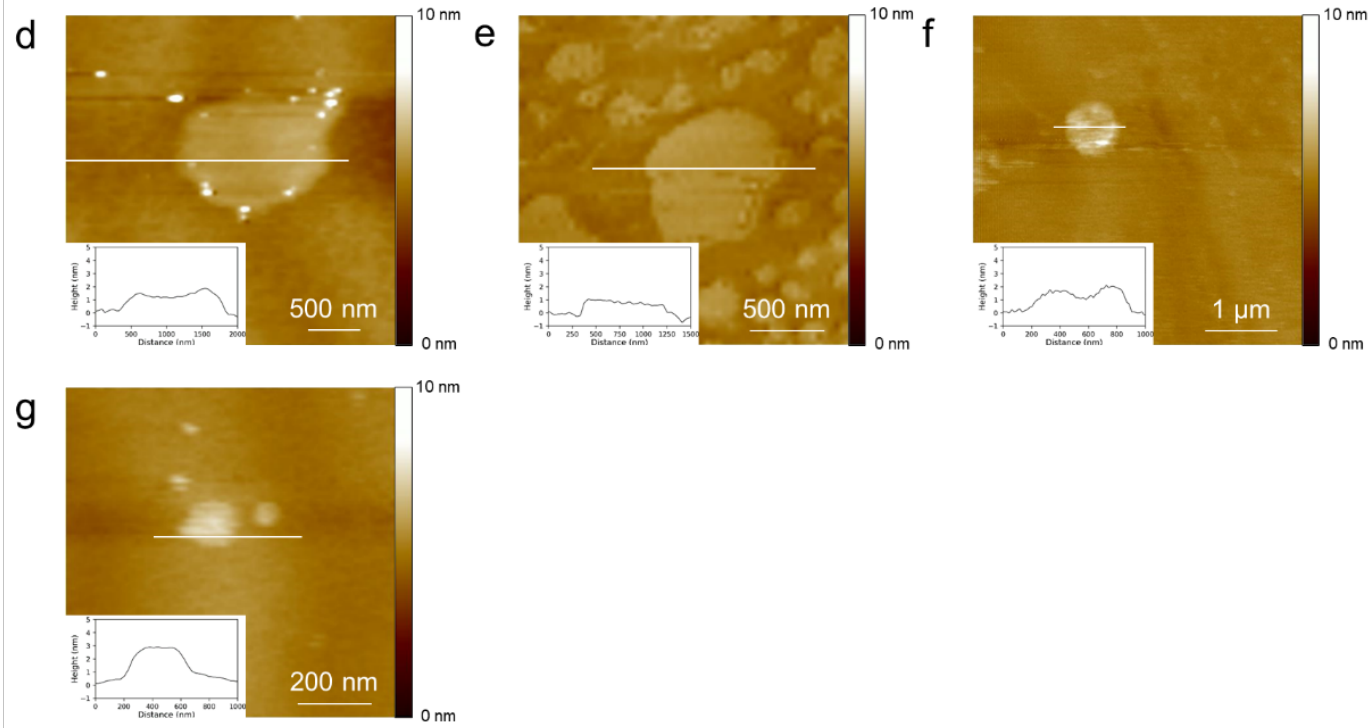

Figure S9. AFM image and cross-section of AuNSs collected from the suspensions. The solvents are (a) hexane, (b) diethyl acetate, (c) ethyl acetate, (d) toluene, (e) chloroform, (f) THF, and (g) acetone. 

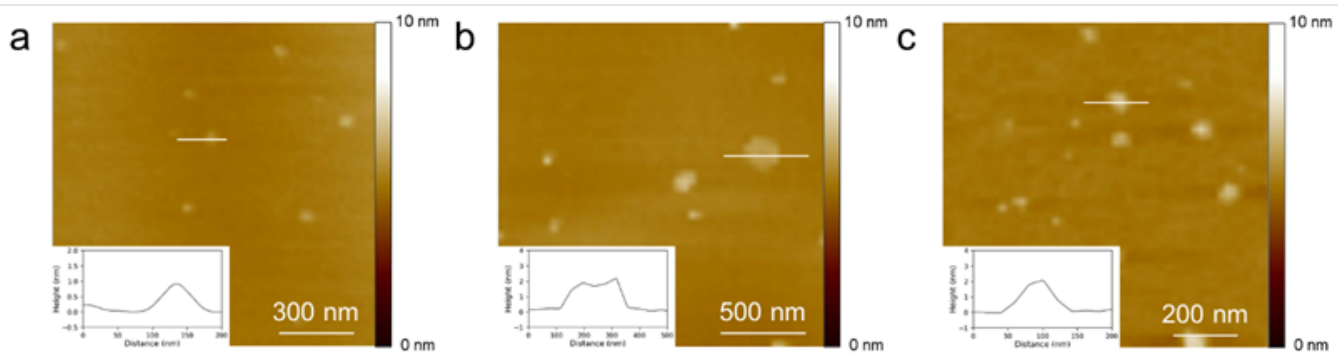

d
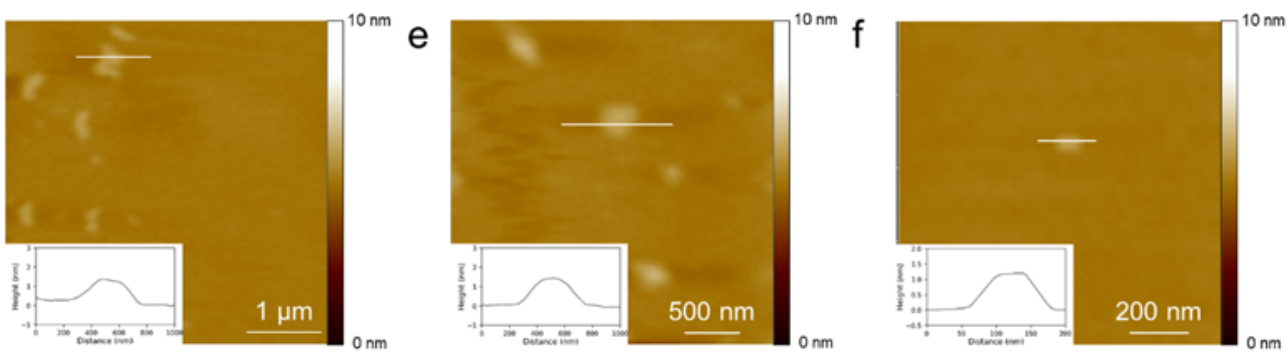

g
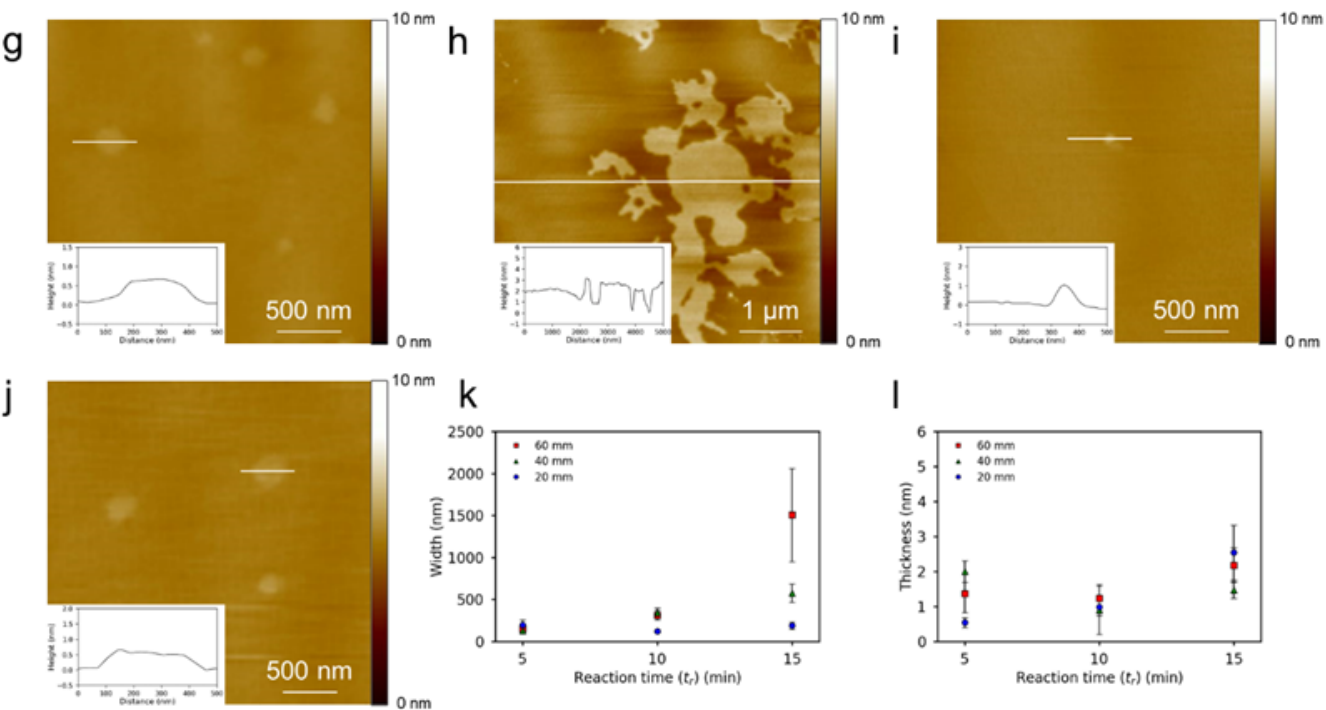

Figure S10. Dependence of width and thickness of AuNSs on $t_{\mathrm{r}}$ and L. AFM image and cross-section of AuNSs for products (a) 8, (b) 9, (c) 10, (d) 11, (e) 12, (f) 13, (g) 14, (h) 15, (i) 16 and (j) 17 listed in Table S2. The dependence of (k) size and (l) thickness of AuNSs on $t_{\mathrm{r}}$ and $L$. 
Table S2. Synthetic conditions for AuNSs in a decane solution of SOBS.

\begin{tabular}{|c|c|c|c|c|c|c|}
\hline Product & $\stackrel{1}{1}$ & $\begin{array}{c}c \\
/ w t \%\end{array}$ & $\begin{array}{c}t_{\mathrm{r}} \\
/ \mathrm{min}\end{array}$ & $\underset{/ \mathrm{mm}}{L}$ & $\begin{array}{l}\text { Size } \\
/ \mathrm{nm}\end{array}$ & $\begin{array}{l}\text { Thickness } \\
/ \mathrm{nm}\end{array}$ \\
\hline 1 & 1.53 & $2.5 \times 10^{-2}$ & 5 & 20 & $129 \pm 29$ & $1.04 \pm 0.65$ \\
\hline 2 & 1.53 & $5.0 \times 10^{-2}$ & 5 & 20 & $198 \pm 57$ & $0.54 \pm 0.14$ \\
\hline 3 & 1.53 & $7.5 \times 10^{-2}$ & 5 & 20 & $141 \pm 36$ & $1.30 \pm 0.22$ \\
\hline 4 & 1.53 & $1.0 \times 10^{-1}$ & 5 & 20 & $150 \pm 47$ & $2.33 \pm 0.91$ \\
\hline 5 & 0.36 & $5.0 \times 10^{-2}$ & 5 & 20 & $119 \pm 23$ & $3.24 \pm 1.75$ \\
\hline 6 & 2.75 & $5.0 \times 10^{-2}$ & 5 & 20 & $78 \pm 27$ & $0.75 \pm 0.32$ \\
\hline 7 & 4.1 & $5.0 \times 10^{-2}$ & 5 & 20 & $105 \pm 29$ & $0.77 \pm 0.37$ \\
\hline 8 & 1.53 & $5.0 \times 10^{-2}$ & 10 & 20 & $120 \pm 16$ & $0.90 \pm 0.25$ \\
\hline 9 & 1.53 & $5.0 \times 10^{-2}$ & 15 & 20 & $189 \pm 43$ & $2.54 \pm 0.78$ \\
\hline 10 & 1.53 & $5.0 \times 10^{-2}$ & 5 & 40 & $128 \pm 14$ & $2.00 \pm 0.31$ \\
\hline 11 & 1.53 & $5.0 \times 10^{-2}$ & 10 & 40 & $342 \pm 53$ & $0.90 \pm 0.69$ \\
\hline 12 & 1.53 & $5.0 \times 10^{-2}$ & 15 & 40 & $576 \pm 108$ & $1.48 \pm 0.24$ \\
\hline 13 & 1.53 & $5.0 \times 10^{-2}$ & 5 & 60 & $153 \pm 26$ & $1.37 \pm 0.56$ \\
\hline 14 & 1.53 & $5.0 \times 10^{-2}$ & 10 & 60 & $311 \pm 53$ & $1.24 \pm 0.39$ \\
\hline 15 & 1.53 & $5.0 \times 10^{-2}$ & 15 & 60 & $1500 \pm 560$ & $2.18 \pm 0.50$ \\
\hline 16 & 1.53 & $5.0 \times 10^{-2}$ & 15 & 15 & $82 \pm 15$ & $0.82 \pm 0.30$ \\
\hline 17 & 1.53 & $5.0 \times 10^{-2}$ & 15 & 30 & $326 \pm 67$ & $3.58 \pm 0.86$ \\
\hline
\end{tabular}



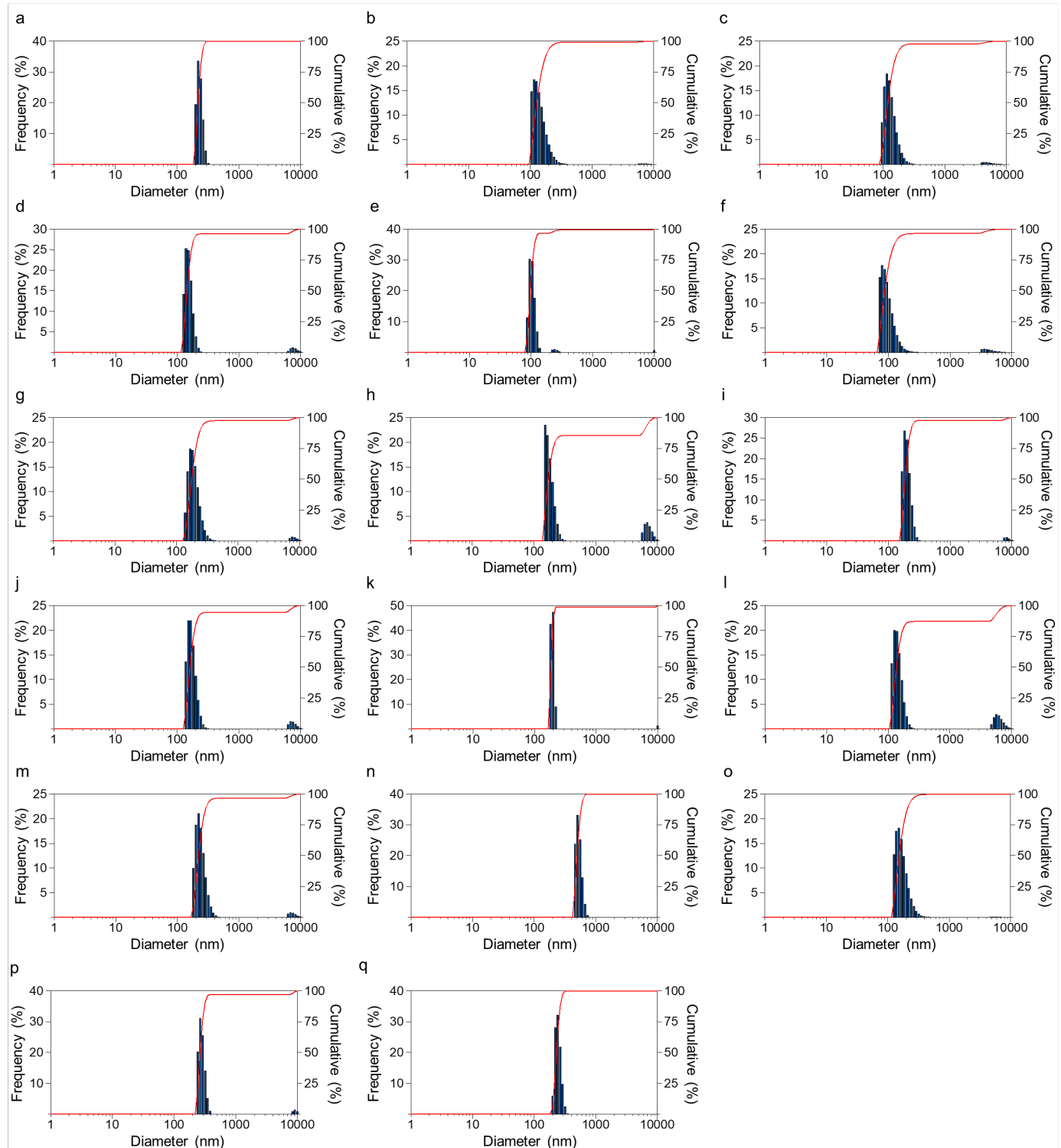

Figure S11. Size distributions of AuNSs in the suspensions. Products (a) 1, (b) 2, (c) 3, (d) 4, (e) 5, (f) 6, (g) 7, (h) 8, (i) 9, (j) 10, (k) 11, (l) 12, (m) 13, (n) 14, (o) 15, (p) 16, and (q) 17 listed in Table S2. 


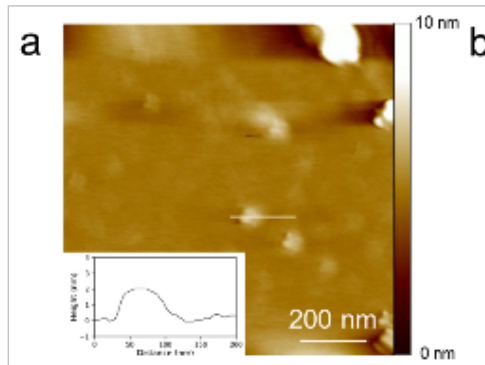

d

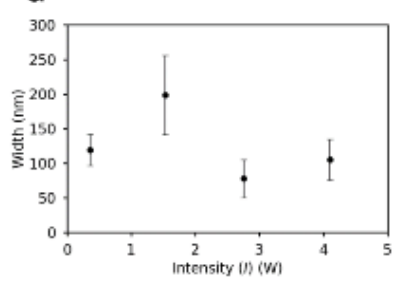

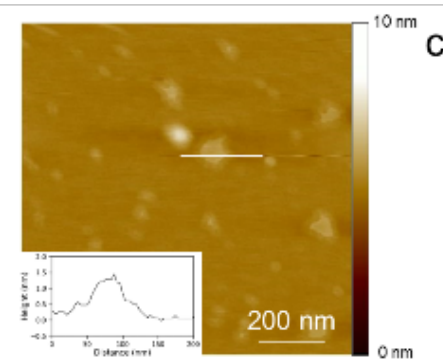

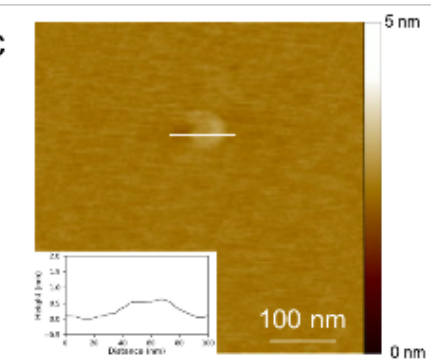

e

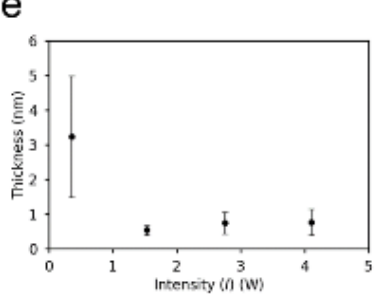

Figure S12. Dependence of width and thickness of AuNSs on I. AFM images and crosssections of AuNSs for products (a) 5 (b) 6 and (c) 7 listed in Table S2. The dependence of (d) size and (e) thickness of AuNSs on $I$.

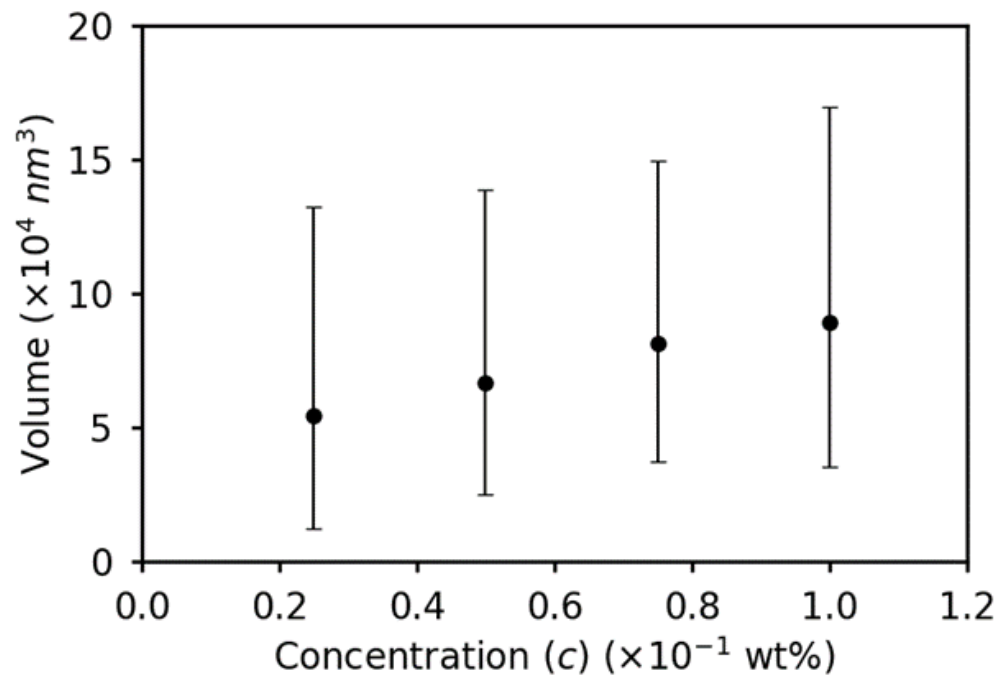

Figure S13. Dependence of volume of AuNSs on $c$. 

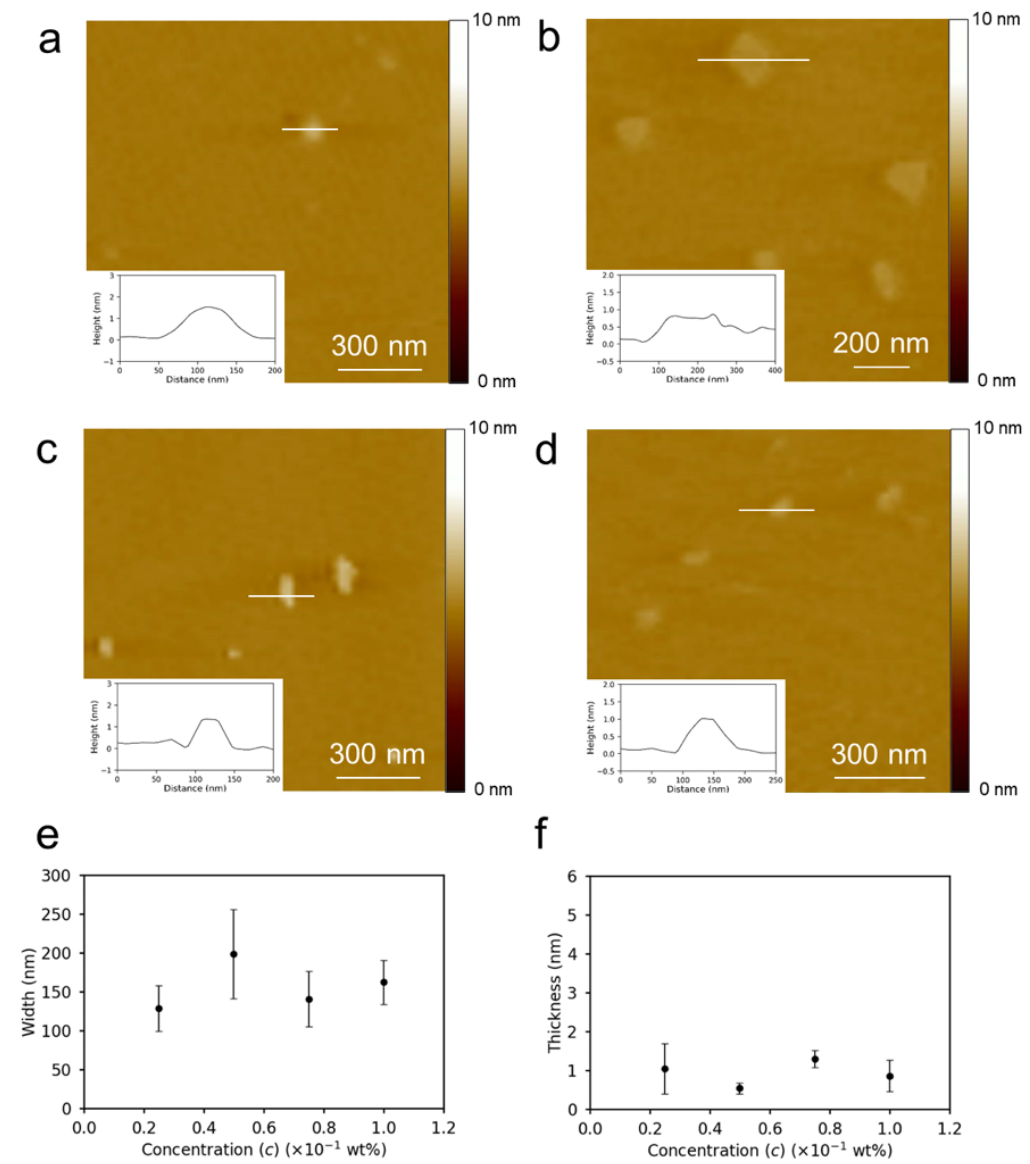

Figure S14. Dependence of width and thickness of AuNSs on $c$. AFM images and crosssections of AuNSs for products (a) 1, (b) 2, (c) 3, and (d) 4 that are listed in Table S2. The dependence of (e) size and (f) thickness of AuNSs on $c$. 
Table S3. Dependence of Reynolds numbers on the length of the agitator.

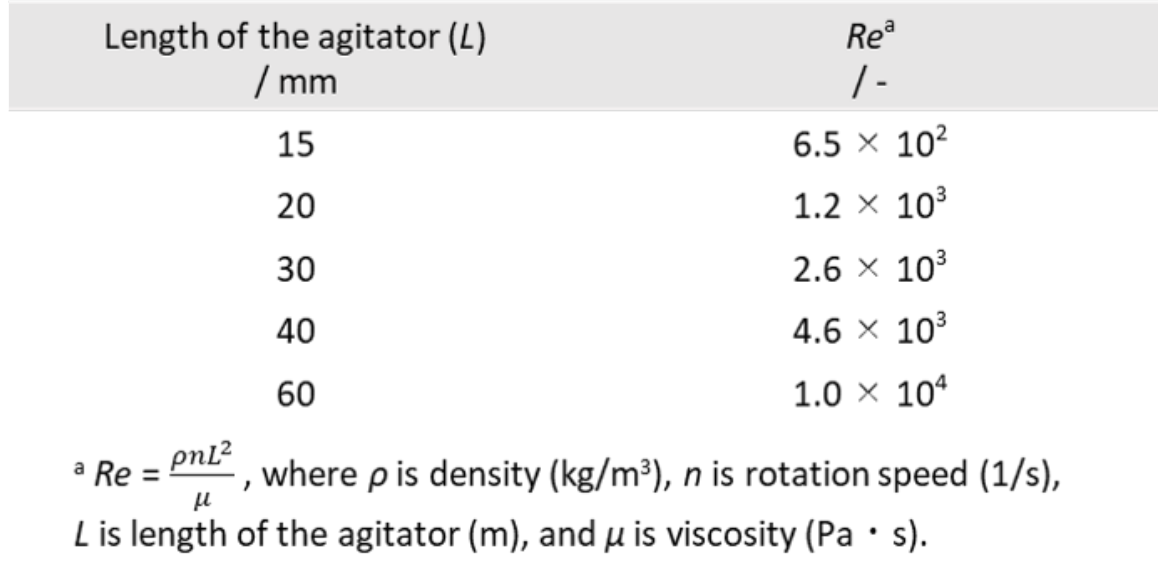
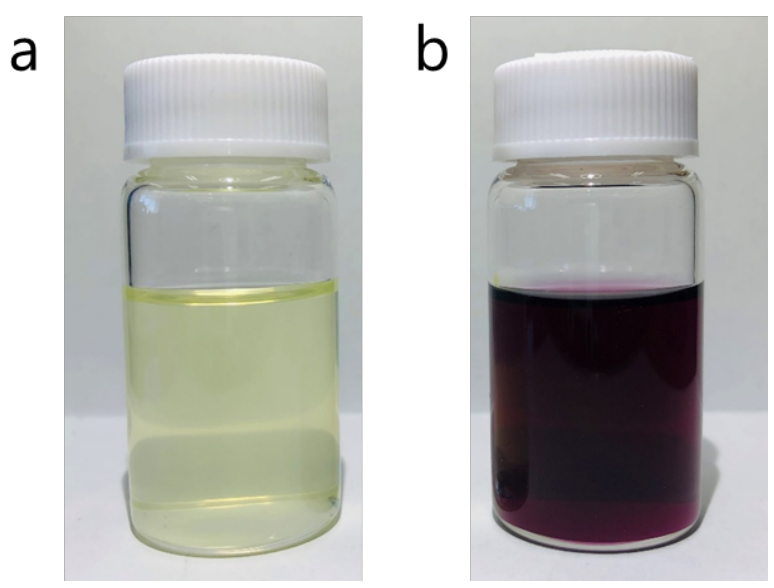

Figure S15. Photographs of hyperswollen lyotropic lamellar phases of the reaction mixtures. These are decane solutions of Brij L4 (7.0 wt\%), water (1.6 wt\%), and $\mathrm{HAuCl}_{4}$ $\left(5.0 \times 10^{-2} \mathrm{wt} \%\right)$. The photographs were taken (a) before the reaction and (b) after the reaction. 

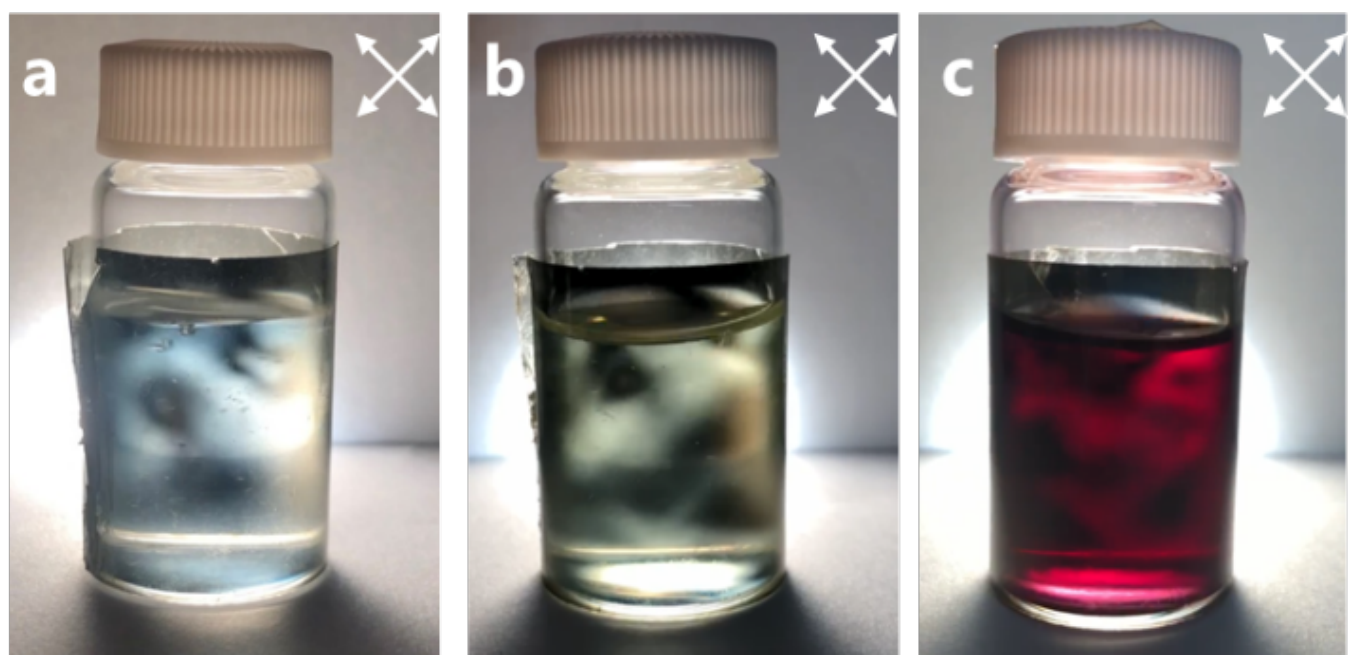

Figure S16. Polarized photographs of hyperswollen lyotropic lamellar phases. (a) Decane solutions of Brij L4 (7.0 wt\%) and water (1.6 wt \%). The reaction mixtures for AuNSs synthesis (b) before reaction and (c) after reaction showed liquid crystalline textures. 
Table S4. Synthetic conditions for AuNSs in a decane solution of Brij L4.

\begin{tabular}{ccccccc} 
Product & \multicolumn{1}{c}{$c$} & $\begin{array}{c}c \\
/ \mathrm{wt} \%\end{array}$ & $\begin{array}{c}t_{\mathrm{r}} \\
/ \mathrm{min}\end{array}$ & $\begin{array}{c}L \\
/ \mathrm{mm}\end{array}$ & $\begin{array}{c}\text { Size } \\
/ \mathrm{nm}\end{array}$ & $\begin{array}{c}\text { Thickness } \\
/ \mathrm{nm}\end{array}$ \\
18 & $1 \mathrm{~W}$ & $5.0 \times 10^{-2}$ & 5 & 20 & $86 \pm 11$ & $2.00 \pm 0.85$ \\
19 & 1.53 & $5.0 \times 10^{-2}$ & 10 & 20 & $102 \pm 13$ & $3.13 \pm 1.34$ \\
20 & 1.53 & $5.0 \times 10^{-2}$ & 15 & 20 & $243 \pm 38$ & $2.54 \pm 0.37$ \\
21 & 1.53 & $5.0 \times 10^{-2}$ & 5 & 40 & $142 \pm 27$ & $1.56 \pm 0.69$ \\
22 & 1.53 & $5.0 \times 10^{-2}$ & 10 & 40 & $167 \pm 28$ & $1.43 \pm 0.72$ \\
23 & 1.53 & $5.0 \times 10^{-2}$ & 15 & 40 & $206 \pm 26$ & $2.69 \pm 0.82$ \\
24 & 1.53 & $5.0 \times 10^{-2}$ & 5 & 60 & $157 \pm 21$ & $1.12 \pm 0.30$ \\
25 & 1.53 & 10 & 60 & $152 \pm 18$ & $2.34 \pm 0.98$ \\
26 & 1.53 & $5.0 \times 10^{-2}$ & 15 & 60 & $211 \pm 35$ & $2.00 \pm 0.66$ \\
\hline
\end{tabular}


a

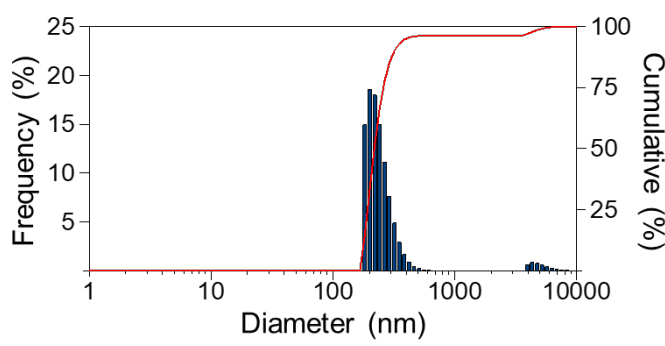

C

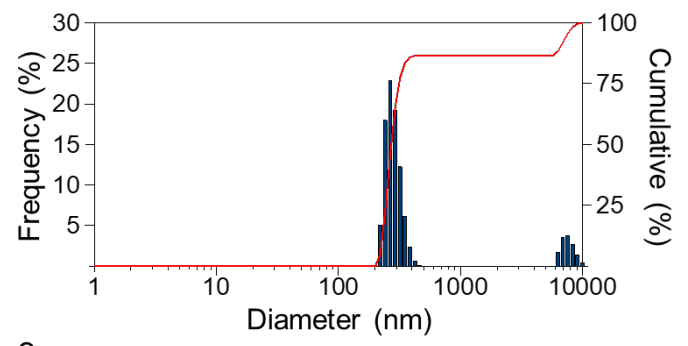

e

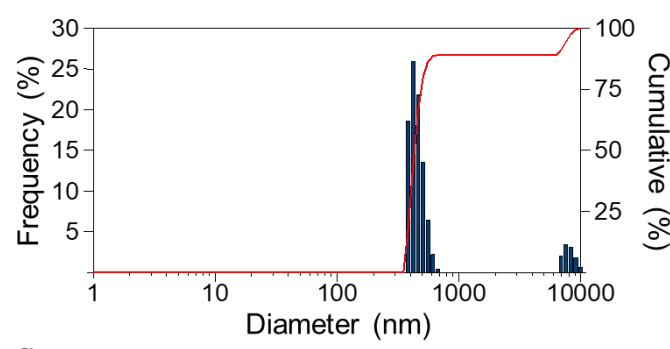

g

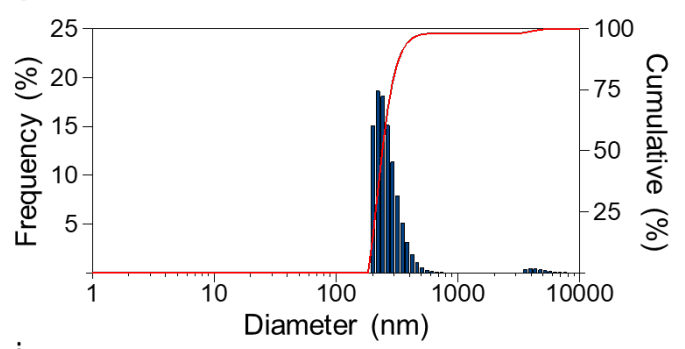

i

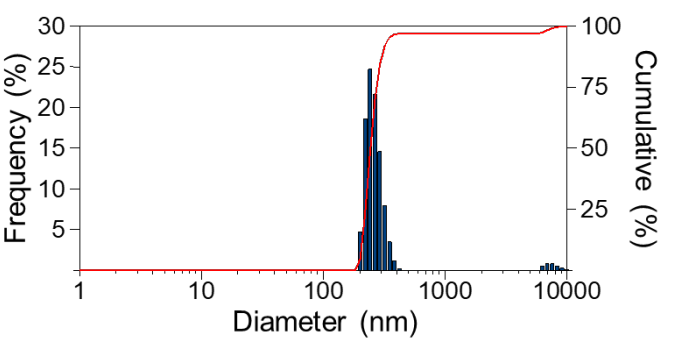

b

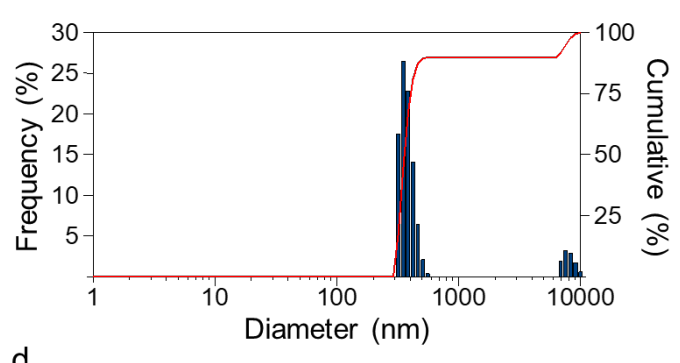

d
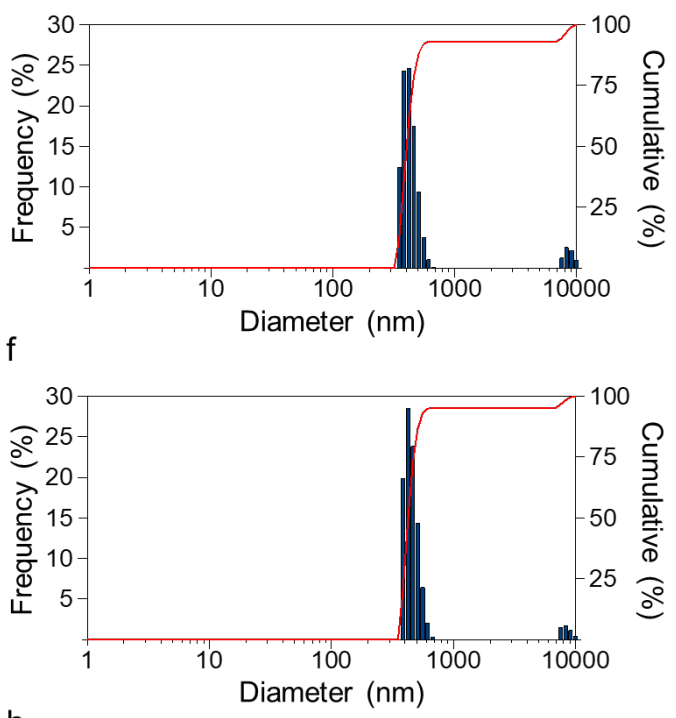

h

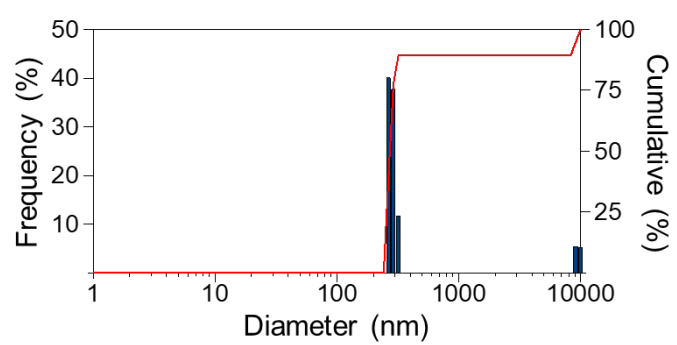

Figure S17. Size distributions of AuNSs in the suspensions. Products (a) 18, (b) 19, (c) 20, (d) 21, (e) 22, (f) 23, (g) 24, (h) 25 and (i) 26 listed in Table S3. 

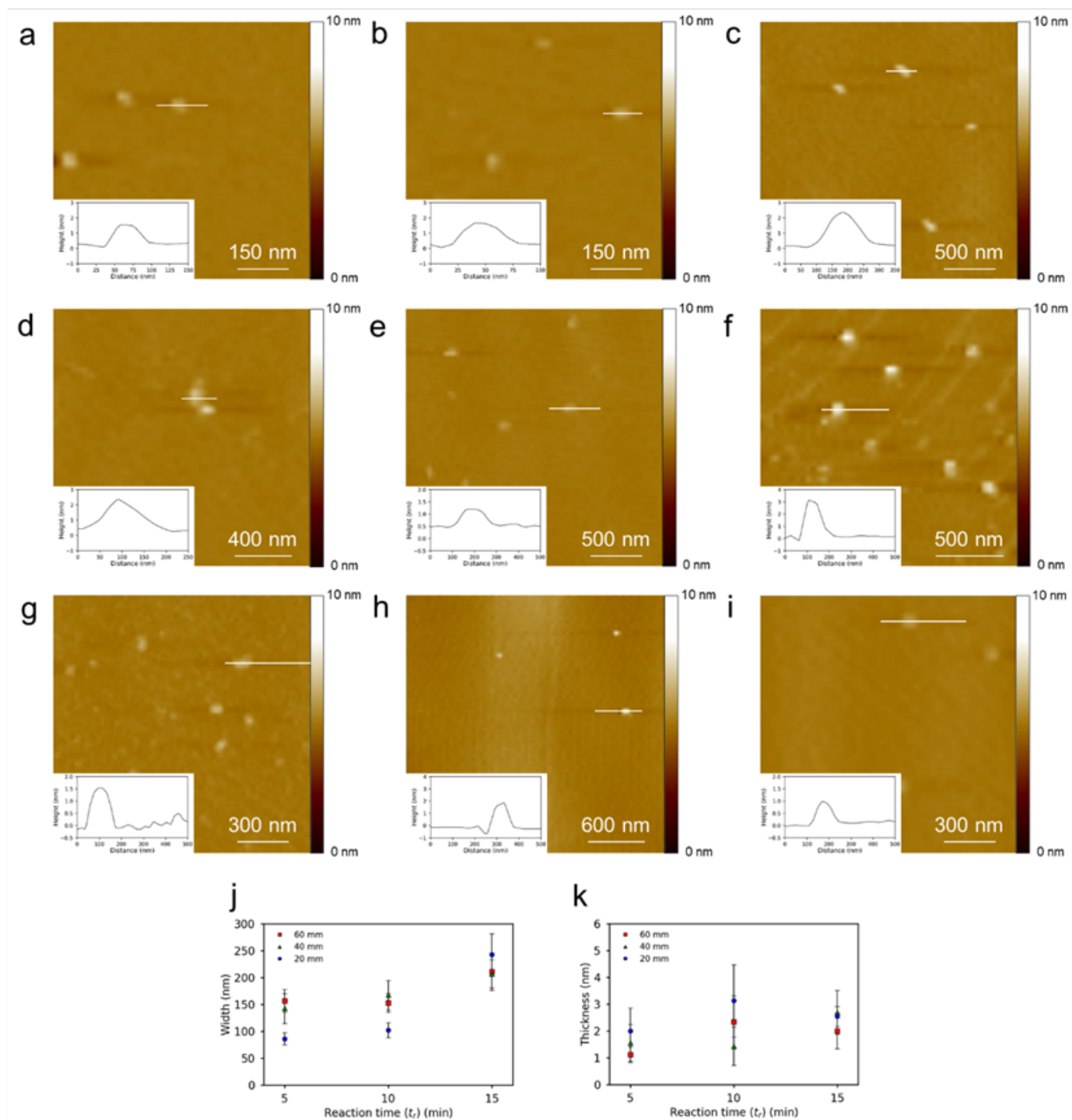

$\mathrm{k}$
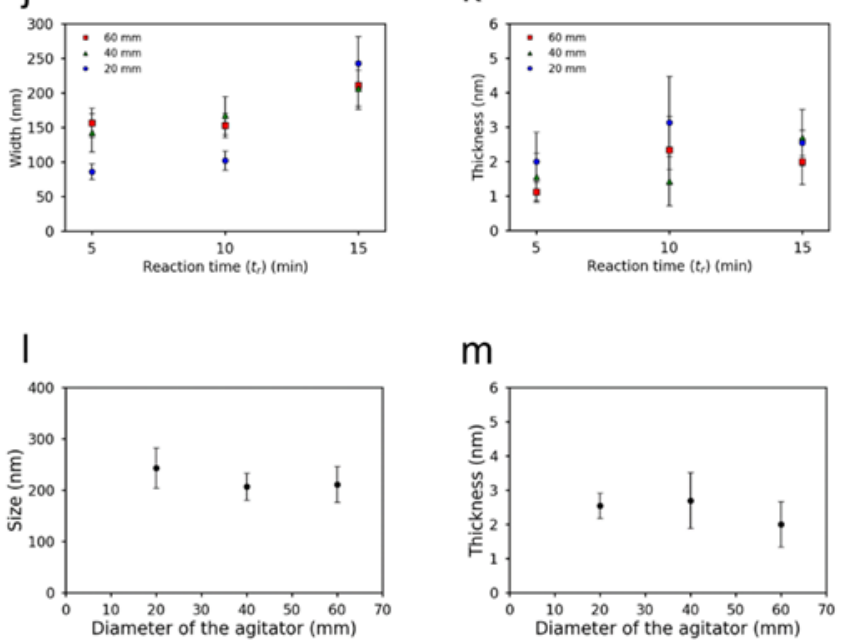

Figure S18. Dependence of width and thickness of AuNSs on $t_{\mathrm{r}}$ and $L$. AFM images and cross-sections of AuNSs for products (a) 18, (b) 19, (c) 20, (d) 21, (e) 22, (f) 23, (g) 24, (h) 25 and (i) 26 listed in Table S3. The dependence of (j) size and (k) thickness of AuNSs on $t_{\mathrm{r}}$ and $L$. The dependence (l) size and (m) thickness of AuNSs on $L$ at 15 minutes. 

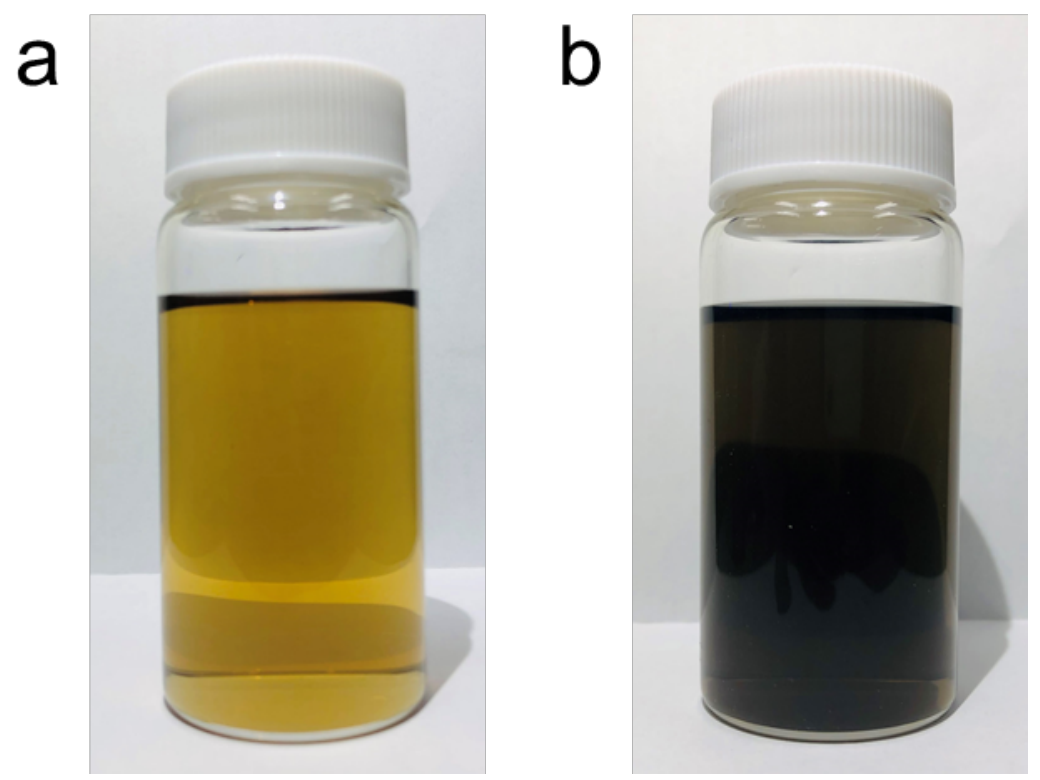

Figure S19. Photographs of hyperswollen lyotropic lamellar phases of the reaction mixtures. These are decane solutions of SOBS (0.95 wt\%), 1-pentanol (8.4 wt\%), water $(1.1 \mathrm{wt} \%)$, sodium hydroxide $(\mathrm{NaOH})\left(2.0 \times 10^{-2} \mathrm{wt} \%\right)$, and silver(I) nitrate $\left(5.0 \times 10^{-2}\right.$ $w t \%)$. The photographs were taken (a) before the reaction and (b) after the reaction.
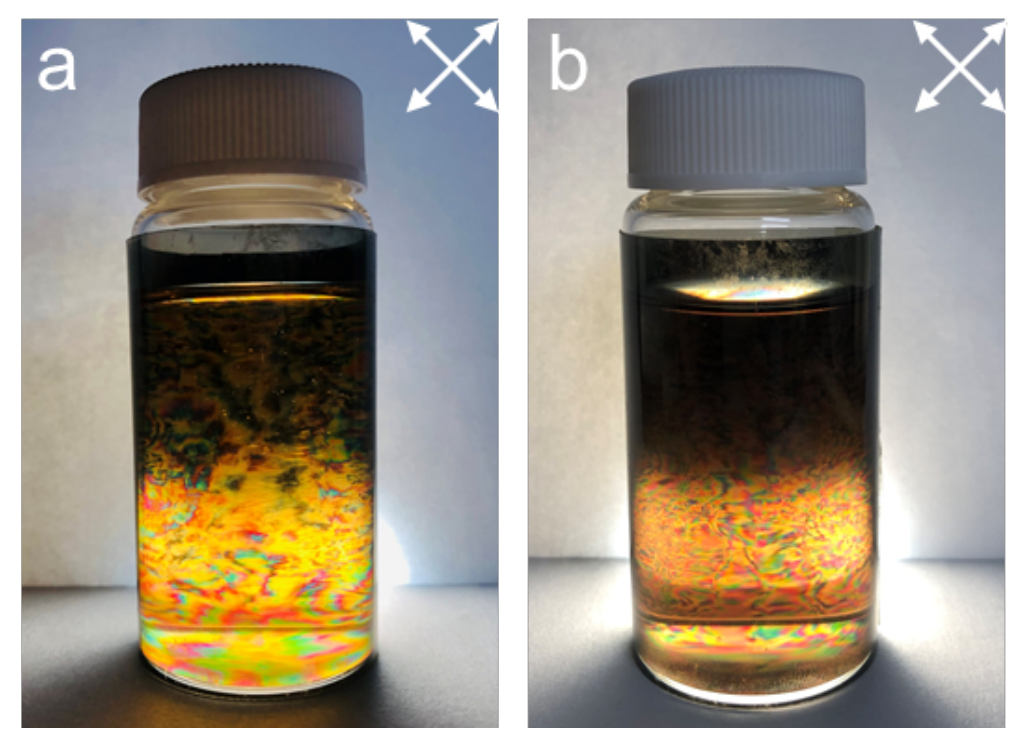

Figure S20. Polarized photographs of hyperswollen lyotropic lamellar phases. Decane solution of SOBS (0.95 wt\%), 1-pentanol (8.4 wt\%), water (1.1 wt\%). The reaction mixture for AgNSs synthesis (a) before reaction and (b) after reaction showed liquid crystalline textures. 

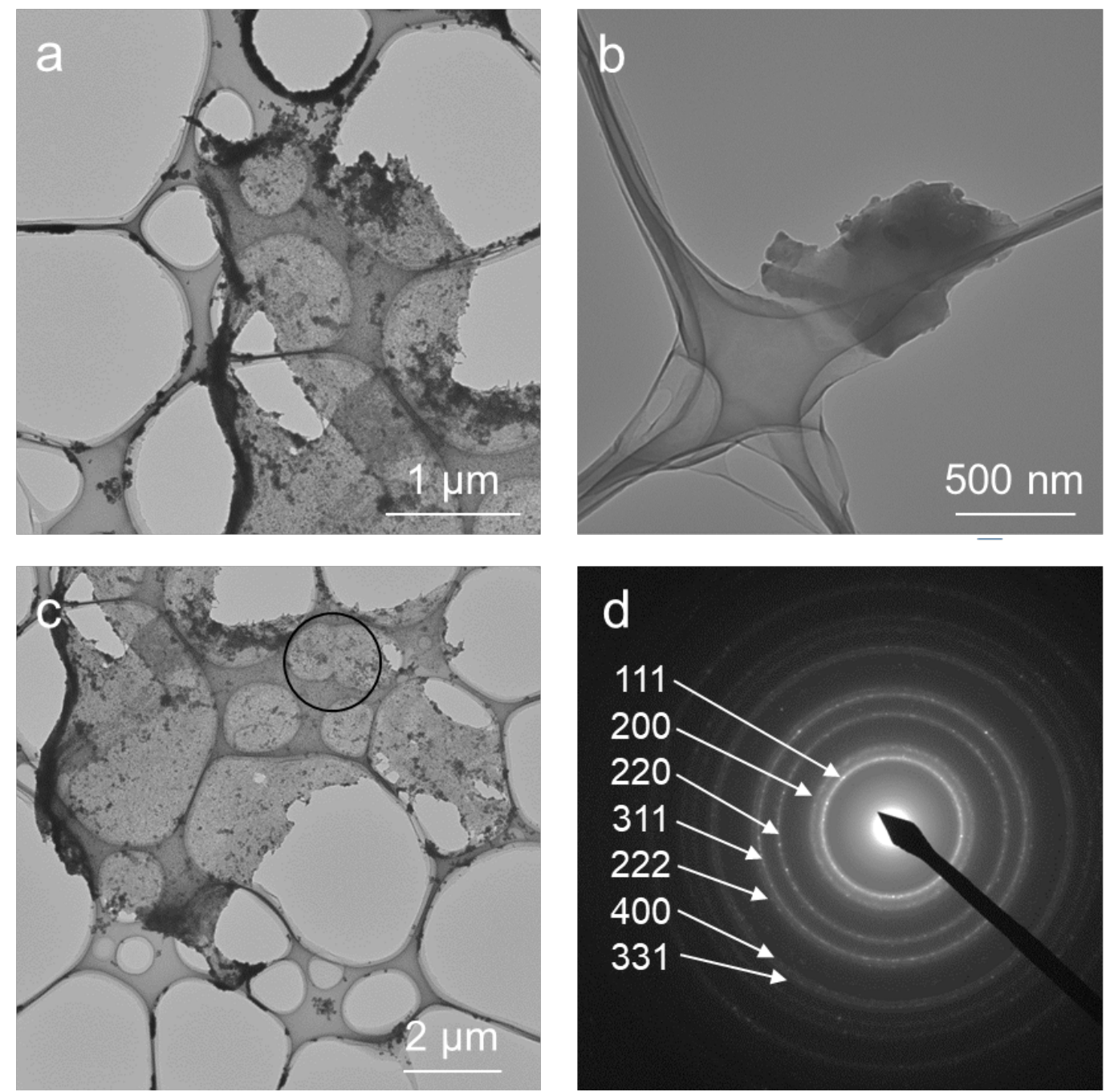

Figure S21. (a)-(c) TEM photographs and (d) selected area electron diffraction pattern of AgNSs.

\section{Reference}

(S1) Madhavi, J. Comparison of average crystallite size by X-ray peak broadening and Williamson-Hall and size-strain plots for $\mathrm{VO}^{2+}$ doped $\mathrm{ZnS} / \mathrm{CdS}$ composite nanopowder. SN Appl. Sci., 2019, 1, 1509. 